(110)

\title{
Monitoring Growth Performance of Naturally Regenerated Woody Species in an Enriched Pine Stand, Sri Lanka
}

\author{
Jayawardhane J.*, Gunaratne A.M.T.A. \\ Department of Botany, Faculty of Science, University of Peradeniya, Sri Lanka \\ *jayaminijayawardhane1@gmail.com
}

\begin{abstract}
Monitoring growth performance of newly recruited plant species after applying several silvicultural treatments in monoculture plantations is important to evaluate the success of forest restoration. This study was conducted in 2015 to determine the growth performance of the naturally regenerated woody plant species in an unrestored (UP) and a restored (RP) Pinus caribaea Morelet plantation, in lower Hantana, Sri Lanka. In RP, partial thinning of pines followed by enrichment planting of four broad-leaved tree species in 2003 and total thinning of pines was initiated in 2009. In both sites fifteen plots $(5 \times 5 \mathrm{~m})$ and within each of them three subplots $(1 \mathrm{x} 1 \mathrm{~m})$ were demarcated randomly. The height of seedlings ( $\mathrm{SE},<50 \mathrm{~cm}$ in height) in subplots and height of saplings $\left(\mathrm{SA}_{1}=50-129\right.$ and $\mathrm{SA}_{2}=130-300 \mathrm{~cm}$ in height $)$ and trees (TR, $>300 \mathrm{~cm}$ in height) and $\mathrm{dbh}$ of $\mathrm{SA}_{2}$ and $\mathrm{TR}$ in all the plots were recorded. Collectively, 417 individuals $(\mathrm{RP}=298, \mathrm{UP}=119)$ representing 28 species $(\mathrm{RP}=24, \mathrm{UP}=12)$ and 22 plant families $(\mathrm{RP}=18, \mathrm{UP}=13)$ survived by the end of the six months. The mean monthly increment of height (MMIH)of survived species in RP was higher for all the life forms except for SE $\left(\mathrm{SE}=1.35, \mathrm{SA}_{1}=1.61, \mathrm{SA}_{2}=1.38, \mathrm{TR}=4.45 \mathrm{cmmo}^{-1}\right)$ than in $\mathrm{UP}\left(\mathrm{SE}=2.06, \mathrm{SA}_{1}=0.17, \mathrm{SA}_{2}=\right.$ $0.00, \mathrm{TR}=1.65 \mathrm{cmmo}^{-1}$ ). The MMIH of trees was significantly higher in RP than UP. The mean monthly increment of dbh (MMID) of survived individuals in RP was higher for both $\mathrm{SA}_{2}\left(0.017 \mathrm{~cm}\right.$ per $\left.\mathrm{mo}^{-1}\right)$ and TR $\left(0.027 \mathrm{~cm}\right.$ per $\left.\mathrm{mo}^{-1}\right)$ than in UP $\left(\mathrm{SA}_{2}=0.0007, \mathrm{TR}=0.024\right.$ $\left.\mathrm{cmmo}^{-1}\right)$. The MMID of $\mathrm{SA}_{2}$ was significantly higher in RP than UP Of the 24 species tested in all four life form categories in RP, $19\left(\mathrm{SE}=39 \%, \mathrm{SA}_{1}=56 \%, \mathrm{SA}_{2}=69 \%\right.$, $\mathrm{TR}=85 \%$ of the species)had MMIH exceeding $1 \mathrm{~cm} \mathrm{mo}^{-1}$ while eight $\left(\mathrm{SA}_{2}=5 \%, \mathrm{TR}=26 \%\right)$ had dbh increment exceeding $0.05 \mathrm{~cm} \mathrm{mo}^{-1}$. In UP, only five species $\left(\mathrm{SE}=60 \%, \mathrm{SA}_{1}=100 \%, \mathrm{SA}_{2}=25 \%\right.$, $\mathrm{TR}=77 \%$ of the species) had MMIH exceeding $1 \mathrm{~cm}$ while one species (Alstonia macrophylla) $\left(\mathrm{SA}_{2}=25 \%, \mathrm{TR}=22 \%\right)$ had MMID exceeding $0.05 \mathrm{~cm} \mathrm{mo}^{-1}$. As the growth performance of the naturally regenerated woody species in RP was higher than UP, we conclude that restoration of pine plantation in mountainous regions of Sri Lanka, using silvicultural techniques is successful in achieving restoration goals.
\end{abstract}

Keywords: Growth performance, Natural regeneration, Pinus plantation, Restoration 